\title{
Prevalence of Cerebral Microhemorrhage following Chronic Blast-Related Mild Traumatic Brain Injury in Military Service Members Using Susceptibility-Weighted MRI
}

\author{
(D) E. Lotan, (D) Morley, (D). Newman, (D). Qian, (D) D. Abu-Amara, (D) C. Marmar, and (D).W. Lui
}

\begin{abstract}
BACKGROUND AND PURPOSE: Cerebral microhemorrhages are a known marker of mild traumatic brain injury. Blast-related mild traumatic brain injury relates to a propagating pressure wave, and there is evidence that the mechanism of injury in blast-related mild traumatic brain injury may be different from that in blunt head trauma. Two recent reports in mixed cohorts of blunt and blast-related traumatic brain injury in military personnel suggest that the prevalence of cerebral microhemorrhages is lower than in civilian head injury. In this study, we aimed to characterize the prevalence of cerebral microhemorrhages in military service members specifically with chronic blast-related mild traumatic brain injury.
\end{abstract}

MATERIALS AND METHODS: Participants were prospectively recruited and underwent 3T MR imaging. Susceptibility-weighted images were assessed by 2 neuroradiologists independently for the presence of cerebral microhemorrhages.

RESULTS: Our cohort included 146 veterans (132 men) who experienced remote blast-related mild traumatic brain injury (mean, 9.4 years; median, 9 years after injury). Twenty-one (14.4\%) reported loss of consciousness for $<30$ minutes. Seventy-seven subjects (52.7\%) had 1 episode of blast-related mild traumatic brain injury; 41 (28.1\%) had 2 episodes; and 28 (19.2\%) had $>2$ episodes. No cerebral microhemorrhages were identified in any subject, as opposed to the frequency of SWI-detectable cerebral microhemorrhages following blunt-related mild traumatic brain injury in the civilian population, which has been reported to be as high as $28 \%$ in the acute and subacute stages.

CONCLUSIONS: Our results may reflect differences in pathophysiology and the mechanism of injury between blast- and blunt-related mild traumatic brain injury. Additionally, the chronicity of injury may play a role in the detection of cerebral microhemorrhages.

ABBREVIATIONS: $\mathrm{CMH}=$ cerebral microhemorrhages; $\mathrm{CTE}=$ chronic traumatic encephalopathy; $\mathrm{mTBI}=$ mild traumatic brain injury; $\mathrm{TBI}=$ traumatic brain injury

B last-related traumatic brain injury (TBI) is of considerable interest in the study of military head trauma due to ongoing United States military deployments in the Middle East and the frequency of exposure to improvised explosive devices. ${ }^{1,2}$ Ten-totwenty percent of veterans returning from Iraq and Afghanistan are estimated to have had TBI with blast exposure, with $>75 \%$ of these classified as mild traumatic brain injury (mTBI) by the

Received February 3, 2018; accepted after revision April 4.

From the Departments of Radiology (E.L., C.M., Y.W.L.) and Psychiatry (I.N., M.Q., D.A.-A., C.M.), Steven and Alexandra Cohen Veterans Center for Posttraumatic Stress and Traumatic Brain Injury, New York University Langone Medical Center, New York, New York; and Sackler Faculty of Medicine (E.L.), Tel Aviv University, Tel Aviv, Israel.

Eyal Lotan is a recipient of Fellowship Grants from the American Physicians Fellowship for Medicine in Israel and from the Dr. Pinchas Borenstein Talpiot Medical Leadership Program 2013.

Main findings previously presented at: Annual Meeting of the American Society of Neuroradiology and the Foundation of the ASNR Symposium, April 20-27, 2017; Long Beach, California.

Please address correspondence to Yvonne W. Lui, MD, 660 1st Ave, Room 336, New York, NY 10016; e-mail: yvonne.lui@nyumc.org

http://dx.doi.org/10.3174/ajnr.A5688
American Congress of Rehabilitative Medicine criteria. ${ }^{2-4}$ Blastrelated TBI results from blast wave-induced changes in atmospheric pressure. ${ }^{5}$ It is clear from several recent studies that blast-related mTBI is associated with remarkable clinical impact, ${ }^{6}$ and chronic traumatic encephalopathy (CTE) has been described on postmortem examinations in individuals with exposure to repeat episodes. ${ }^{7}$ How a pressure wave damages the brain is the subject of debate dating back to the post-World War II period. ${ }^{8-10}$ A few recent reports using in vivo diffusion MR imaging showed a reduction in white matter fractional anisotropy in patients with blast-related $\mathrm{mTBI}^{11-15}$ in a pattern that may be distinct from civilian blunt-related mTBI. ${ }^{16}$ It has been suggested that blastrelated $\mathrm{mTBI}$ represents a unique injury mechanism distinct from blunt head trauma. ${ }^{9,17,18}$ There is current interest in specifically characterizing patients who have experienced blast-related mTBI and in determining whether there are unique features of this type of injury.

Cerebral microhemorrhage is a clear imaging biomarker associated with mTBI seen distinctly on conventional MR imaging using susceptibility-weighted imaging. ${ }^{19,20}$ Studies in civilians 
following acute and subacute blunt mTBI have reported that the frequency of SWI-detected cerebral microhemorrhages (CMH) ranged from $19 \%$ to $28 \% .^{21-24} \mathrm{~A}$ few recent works have suggested a lower prevalence in military personnel with chronic mTBI compared with civilians, ${ }^{3,25,26}$ though these studies were of mixed cohorts, including both blast- and blunt-related TBI and a range of injury severity. ${ }^{3,25}$ Riedy et $\mathrm{al}^{3}$ and Liu et $\mathrm{al}^{25}$ found an approximately $3 \%-4 \%$ prevalence of $\mathrm{CMH}$ in subjects with a mixed history of blast- and blunt-related mTBI. The true prevalence of $\mathrm{CMH}$ in blast-related mTBI is not known. The purpose of the current study was to characterize $\mathrm{CMH}$ in military service members with chronic blast-related mTBI.

\section{MATERIALS AND METHODS \\ Participants and Measures}

Subjects in this study were drawn from an ongoing prospective study of military veterans performed at the NYU Langone Medical Center. The study was approved by the local institutional review board. All participants provided written informed consent. Inclusion criteria for this study were the following: military service in Operation Enduring Freedom, Operation Iraqi Freedom, and/or Operation New Dawn; between 18 and 70 years; and clinical diagnosis of mTBI in conjunction with close proximity to a blast explosion without concomitant blunt traumatic head injury based on the Department of Veterans Affairs and the Department of Defense definition of $\mathrm{mTBI}^{27}$ (including altered mental state for $<24$ hours and no or $<30$ minutes loss of consciousness) as elicited by the Ohio State University TBI Identification MethodShort Form. ${ }^{28}$ Subjects were excluded with a history of comorbid major neurologic disorder or systemic illness, a history of severe drug use disorder, psychosis, suicidality, homicidality, a history of prior moderate or severe head injury, or contraindications to MR imaging. All participants completed a formal, self-report measure of postconcussion symptoms. Symptom severity and quantity were measured using the Concussion Symptom Inventory, a list of 12 symptoms that are graded in severity by the patient on a 7-point Likert scale. ${ }^{29}$ The maximum Concussion Symptom Inventory score is 72 , indicating maximum overall symptom severity. Additionally, to assess the impact of headache, we used the Headache Impact Test- 6 score. ${ }^{30}$ This score ranges between 36 and 78, with larger scores reflecting greater impact and a score of $>50$ considered an abnormal finding. All participants were administered the 2-factor model from the Wechsler Adult Intelligence Scale, 2nd ed, ${ }^{31}$ which uses vocabulary and matrix reasoning subtests to estimate intelligence quotient.

\section{MR Imaging}

Participants were imaged at 3T (Skyra; Siemens, Erlangen, Germany) using a 20-channel head coil. SWI was performed with the following parameters: $\mathrm{TR}=29 \mathrm{~ms}, \mathrm{TE}=20 \mathrm{~ms}$, flip angle $=15^{\circ}$, slice thickness $=2 \mathrm{~mm}$, intersection gap $=0 \mathrm{~mm}$, FOV $=158 \times$ $220 \mathrm{~mm}$, matrix $=261 \times 448$, generalized autocalibrating partially parallel acquisition factor $=2$. Conventional MR imaging, including T1-weighted imaging, T2-weighted imaging, T2weighted FLAIR imaging, and diffusion-weighted imaging, was also performed. SWI and conventional MR imaging sequences were reviewed independently by 2 neuroradiologists (1 second-
Table 1: Demographic and clinical characteristics ( $N=146)$

\begin{tabular}{lcc}
\multicolumn{1}{c}{ Variable } & No. & $\%$ \\
\hline Ethnicity & & \\
$\quad$ White & 84 & 57.5 \\
Hispanic & 31 & 21.2 \\
African American & 17 & 11.6 \\
Asian & 9 & 6.2 \\
$\quad$ Other & 5 & 3.4 \\
Tours of duty & & \\
0 & 7 & 4.8 \\
1 & 55 & 37.7 \\
2 & 48 & 32.9 \\
3 & 19 & 13.0 \\
$\geq 4$ & 17 & 11.6 \\
Episodes of blast-related mTBI & & \\
1 & 77 & 52.7 \\
2 & 41 & 28.1 \\
$\geq 3$ & 28 & 19.2 \\
Hypertension & 19 & 13.0 \\
\hline
\end{tabular}

Table 2: Demographic and clinical characteristics $(N=146)^{a}$

\begin{tabular}{lrr}
\hline \multicolumn{1}{c}{ Variable } & Mean & SD \\
\hline Time since mTBI (yr) & 9.4 & 6.2 \\
Deployment time (yr) & 5.7 & 3.5 \\
WASI-II IQ (standard score) & 106.6 & 13.3 \\
HIT-6 score & 45.8 & 9.3 \\
CSI & 12.5 & 14.0 \\
\hline
\end{tabular}

Note:-WASI-II indicates Wechsler Adult Intelligence Scale, 2nd ed; IQ, intelligence quotient; HIT-6 = Headache Impact Test-6; CSI = Concussion Symptom Inventory ${ }^{a}$ The maximum $\mathrm{CSI}$ and $\mathrm{HTI}-6$ score is 72 , indicating maximum symptom severity.

year neuroradiology fellow [E.L] and 1 attending neuroradiologist with $>10$ years of experience [Y.W.L]). Susceptibilityweighted images were reviewed for quality in terms of susceptibility seen in expected locations such as venous structures and calcification of the choroid plexus, or for the presence of any artifacts. The presence of CMH was determined using the Greenberg criteria, including a round or ovoid signal at least half surrounded by brain parenchyma with a dipole effect on SWI phase imaging and distinct from other potential mimics (calcium deposits, bone, air, or vessel flow voids). ${ }^{32,33}$

\section{RESULTS}

One-hundred forty-six subjects were identified with a history of blast-related mTBI (132 men, 14 women). Demographic and clinical data for the present sample are reported in Tables 1 and 2 . The mean age was $32.8 \pm 7.4$ years (median, 31 years; range, 22-66 years). The time interval from the last injury to MR imaging ranged from 1 to 31 years (mean, $9.4 \pm 6.2$ years; median, 9 years). Sixty-nine subjects $(47.3 \%)$ had $\geq 2$ episodes. Twenty-one (14.4\%) reported loss of consciousness with their injury of $<30$ minutes, and $85.6 \%$ had altered mental status. Subjects had a normal distribution of IQ and demonstrated mild headache pain and postconcussive symptoms (Tables 1 and 2). No CMH were detected by either neuroradiologist. One subject (1\%) had cerebellar ectopia, 7 (5\%) had developmental venous anomalies, 48 (33\%) had some degree of white matter abnormality (ie, T2 hyperintensity), 3 (2\%) had arachnoid cysts, and 54 (37\%) had sinus disease. No other structural abnormalities were identified. No images demonstrated artifacts warranting exclusion. 


\begin{tabular}{|c|c|c|c|c|c|c|}
\hline Authors & Population & $\begin{array}{l}\text { Mechanism } \\
\text { of mTBI }\end{array}$ & $\begin{array}{l}\text { Prevalence } \\
\text { of } \mathrm{CMH}\end{array}$ & $\begin{array}{l}\text { Time } \\
\text { since } \\
\text { mTBI }\end{array}$ & MRI & $\begin{array}{c}\text { Voxel } \\
\text { Size }(\mathrm{mm})\end{array}$ \\
\hline van der Horn et al $(2017)^{24}$ & Civilian & Blunt & $15 / 54(28 \%)$ & 33 days & SWI (3T) & $0.9 \times 0.9 \times 2$ \\
\hline Trifan et al $(2017)^{34}$ & Civilian & Blunt & $26 / 150$ (17\%) & 29 months & SWI (3T) & $0.5 \times 0.5 \times 2$ \\
\hline Toth et al $(2018)^{35}$ & Civilian & Blunt & $1 / 13(8 \%)$ & 2 years & SWI (3T) & $1.0 \times 0.9 \times 1.5$ \\
\hline Huang et al $(2015)^{22}$ & Civilian & Blunt & $23 / 111(23 \%)$ & 25 days & SWI (3T) & $0.5 \times 0.5 \times 2$ \\
\hline Wang et al $(2014)^{23}$ & Civilian & Blunt & $32 / 165$ (19\%) & $\leq 3$ days & SWI (3T) & $0.7 \times 0.7 \times 1.2$ \\
\hline Yuh et al $(2013)^{21}$ & Civilian & Blunt & $23 / 98(23 \%)$ & 12 days & $\begin{array}{l}\text { T2*-weighted } \\
\text { GRE }(1.5 / 3 T)\end{array}$ & NA \\
\hline Topal et al $(2008)^{36}$ & Civilian & Blunt & $4 / 40(10 \%)$ & $<1$ day & $\begin{array}{c}\text { T2}^{*} \text {-weighted } \\
\text { GRE (1.5T) }\end{array}$ & NA \\
\hline Tate et al $(2017)^{26}$ & Military members & Mixed blunt and blast & $9 / 77(12 \%)$ & 309 days & SWI (3T) & $1.0 \times 0.9 \times 1.5$ \\
\hline Liu et al $(2016)^{25}$ & Military members & Mixed blunt and blast & $18 / 559(3 \%)$ & 1325 days & SWI (3T) & $0.5 \times 0.9 \times 1.5$ \\
\hline Riedy et al $(2016)^{3}$ & Military members & Mixed blunt and blast & $29 / 768(4 \%)$ & 1381 days & SWI (3T) & $0.5 \times 0.9 \times 1.5$ \\
\hline Current study (2018) & Military members & Blast & $0 / 146(0 \%)$ & 9 years & SWI (3T) & $0.5 \times 0.6 \times 2$ \\
\hline
\end{tabular}

Note:-NA indicates not applicable; GRE, gradient recalled-echo.

\section{DISCUSSION}

In this cohort of 146 veterans with exposure to chronic blastrelated mTBI, with approximately half exposed to multiple blast episodes in multiple tours during 5 years of deployment time, no foci of $\mathrm{CMH}$ were detected at $3 \mathrm{~T} \mathrm{MR}$ imaging using SWI. The overall prevalence of $\mathrm{CMH}$ in our cohort of well-characterized subjects with a history of chronic military blast-related mTBI was low compared with previous reports of civilian blunt-related mTBI. ${ }^{21-24,34-36}$ There is a mix of literature and findings in terms of the mechanism of injury (blunt or mixed population of bluntand blast-related mTBI), prevalence of $\mathrm{CMH}$, variable cohorts (military or civilian), variable time since injury, and the MR imaging techniques used for $\mathrm{CMH}$ detection. The literature is summarized in Table 3. ${ }^{3,21-26,34-36}$ Our findings are in keeping with Liu et $\mathrm{al}^{25}$ and Riedy et $\mathrm{al}^{3}{ }^{3}$ who reported $3 \%-4 \%$ prevalence of $\mathrm{CMH}$ in a mixed group of military service members with a chronic history of either blunt- or blast-related mTBI. Technical differences between the current study and prior studies do not account for differences in $\mathrm{CMH}$ prevalence. The acquisition and protocol used in the current study are comparable with those in multiple other recent studies (Table 3).

The undetectable prevalence of $\mathrm{CMH}$ in the current cohort of 146 subjects with blast-related mTBI supports the evolving notion that blast-related mTBI has not only a unique mechanism of injury but also a unique pathophysiology that may be distinct from blunt trauma-induced mTBI. ${ }^{9,17,18}$ In addition, despite the longstanding idea that brain hemosiderin remains in clusters of ironladen macrophages in perivascular spaces for the long term, ${ }^{37-39}$ there may be variability in the detection of $\mathrm{CMH}$ relating to the evolution of blood products, particularly in the acute and subacute phases after injury. ${ }^{40}$ The sensitivity for $\mathrm{CMH}$ may diminish with time as has been suggested by Liu et al. ${ }^{25}$ Furthermore, in an 8 -year longitudinal study of nontraumatic $\mathrm{CMH}$ using SWI, the hemorrhages persisted across time, with a slight decrease in volume. ${ }^{41}$ Nevertheless, 2 recently published studies on civilian patients with chronic blunt-related mTBI demonstrated a $\mathrm{CMH}$ prevalence of $8 \%-17 \% .^{34,35}$ This suggests that while $\mathrm{CMH}$ may evolve between the acute and chronic phases after injury, the prevalence of chronic blast-related mTBI CMH that we report here remains lower than in previous reports of blunt-related injury.
Limitations of this study include a retrospective self-report of injury, though a prospective study including acutely injured subjects is challenging due to the limitations of MR imaging availability in remote military sites. Furthermore, the Ohio State University TBI Identification Method is considered a reliable and valid tool for assessing TBI and was selected on the basis of its high interrater reliability. ${ }^{28}$ An additional limitation is the variability of the time since injury compared with the previous studies, particularly because there is evidence that $\mathrm{CMH}$ may evolve.

\section{CONCLUSIONS}

We found that no individuals in the 146 subjects with chronic blast-related mTBI had evidence of CMH on 3T SWI. This finding may suggest a substantially lower prevalence of $\mathrm{CMH}$ in this cohort of subjects with blast-related mTBI compared with previous reports, primarily in civilian chronic blunt-related $\mathrm{mTBI},{ }^{34,35}$ and may reflect differences in the mechanism and pathophysiology of injury. However, due to possible degradation of $\mathrm{CMH}$ with time, the chronicity of injury may play a role in the detection of $\mathrm{CMH}$, and future studies will be needed to assess the prevalence of $\mathrm{CMH}$ in the more acute settings.

Disclosures: The project described was made possible with support by grants from the Steven A. and Alexandra M. Cohen Foundation, Inc. and Cohen Veterans Bioscience, Inc. (CVB) to NYU School of Medicine. The content is solely the responsibility of the authors and does not necessarily represent the official views of the Foundation or CVB.

\section{REFERENCES}

1. Shively SB, Perl DP. Traumatic brain injury, shell shock, and posttraumatic stress disorder in the military: past, present, and future. J Head Trauma Rehabil 2012;27:234-39 CrossRef Medline

2. Hoge CW, McGurk D, Thomas JL, et al. Mild traumatic brain injury in U.S. soldiers returning from Iraq. N Engl J Med 2008;358:453-63 CrossRef Medline

3. Riedy G, Senseney JS, Liu W, et al. Findings from structural MR imaging in military traumatic brain injury. Radiology 2016;279: 207-15 CrossRef Medline

4. Kay T, Harrington DE, Adams R, et al. Definition of mild traumatic brain injury. J Head Trauma Rehabil 1993;8:86-87 CrossRef

5. DePalma RG, Burris DG, Champion HR, et al. Blast injuries. N Engl J Med 2005;352:1335-42 CrossRef Medline

6. Mac Donald CL, Barber J, Jordan M, et al. Early clinical predictors of 
5-year outcome after concussive blast traumatic brain injury. JAMA Neurol 2017;74:821-29 CrossRef Medline

7. Mayer AR, Quinn DK, Master CL. The spectrum of mild traumatic brain injury: a review. Neurology 2017;89:623-32 CrossRef Medline

8. Denny-Brown D. Cerebral concussion. Physiol Rev 1945;25:296-325 CrossRef

9. Elder GA, Stone JR, Ahlers ST. Effects of low-level blast exposure on the nervous system: is there really a controversy? Front Neurol 2014; 5:269 CrossRef Medline

10. Courtney A, Courtney M. The complexity of biomechanics causing primary blast-induced traumatic brain injury: a review of potential mechanisms. Front Neurol 2015;6:221 CrossRef Medline

11. Ivanov I, Fernandez C, Mitsis EM, et al. Blast exposure, white matter integrity, and cognitive function in Iraq and Afghanistan combat veterans. Front Neurol 2017;8:127 CrossRef Medline

12. Mac Donald CL, Barber J, Andre J, et al. 5-Year imaging sequelae of concussive blast injury and relation to early clinical outcome. Neuroimage Clin 2017;14:371-78 CrossRef Medline

13. Trotter BB, Robinson ME, Milberg WP, et al. Military blast exposure, ageing and white matter integrity. Brain 2015;138:2278-92 CrossRef Medline

14. Mac Donald CL, Johnson AM, Cooper D, et al. Detection of blastrelated traumatic brain injury in U.S. military personnel. $N$ Engl J Med 2011;364:2091-100 CrossRef Medline

15. Taber KH, Hurley RA, Haswell CC, et al. White matter compromise in veterans exposed to primary blast forces. J Head Trauma Rehabil 2015;30:E15-25 CrossRef Medline

16. Davenport ND, Lim KO, Armstrong MT, et al. Diffuse and spatially variable white matter disruptions are associated with blast-related mild traumatic brain injury. Neuroimage 2012;59:2017-24 CrossRef Medline

17. Bhattacharjee Y. Neuroscience: shell shock revisited—solving the puzzle of blast trauma. Science 2008;319:406-08 CrossRef Medline

18. Fischer B, Parsons M, Durgerian S, et al. Neural activation during response inhibition differentiates blast from mechanical causes of mild to moderate traumatic brain injury. J Neurotrauma 2014;31: 169-79 CrossRef Medline

19. Haacke EM, Mittal S, Wu Z, et al. Susceptibility-weighted imaging: technical aspects and clinical applications, part 1. AJNR Am J Neuroradiol 2009;30:19-30 CrossRef Medline

20. Bigler ED, Maxwell WL. Neuropathology of mild traumatic brain injury: relationship to neuroimaging findings. Brain Imaging Behav 2012;6:108-36 CrossRef Medline

21. Yuh EL, Mukherjee P, Lingsma HF, et al; TRACK-TBI Investigators. Magnetic resonance imaging improves 3-month outcome prediction in mild traumatic brain injury. Ann Neurol 2013;73:224-35 CrossRef Medline

22. Huang YL, Kuo YS, Tseng YC, et al. Susceptibility-weighted MRI in mild traumatic brain injury. Neurology 2015;84:580-85 CrossRef Medline

23. Wang X, Wei XE, Li MH, et al. Microbleeds on susceptibilityweighted MRI in depressive and non-depressive patients after mild traumatic brain injury. Neurol Sci 2014;35:1533-39 CrossRef Medline

24. van der Horn HJ, de Haan S, Spikman JM, et al. Clinical relevance of microhemorrhagic lesions in subacute mild traumatic brain injury.
Brain Imaging Behav 2017 Jun 29. [Epub ahead of print] CrossRef Medline

25. Liu W, Soderlund K, Senseney JS, et al. Imaging cerebral microhemorrhages in military service members with chronic traumatic brain injury. Radiology 2016;278:536-55 CrossRef Medline

26. Tate DF, Gusman M, Kini J, et al. Susceptibility weighted imaging and white matter abnormality findings in service members with persistent cognitive symptoms following mild traumatic brain injury. Mil Med 2017;182:e1651-58 CrossRef Medline

27. O'Neil ME, Carlson K, Storzbach D, et al. Complications of mild traumatic brain injury in veterans and military personnel: a systematic review [Internet]. Washington, DC: Department of Veterans Affairs; 2013

28. Corrigan JD, Bogner J. Initial reliability and validity of the Ohio State University TBI Identification Method. J Head Trauma Rehabil 2007;22:318-29 CrossRef Medline

29. Randolph C, Millis S, Barr WB, et al. Concussion Symptom Inventory: an empirically-derived scale for monitoring resolution of symptoms following sports-related concussion. Arch Clin Neuropsychol 2009;24:219-29 CrossRef Medline

30. Kosinski M, Bayliss MS, Bjorner JB, et al. A six-item short-form survey for measuring headache impact: the HIT-6. Qual Life Res 2003 12:963-74 CrossRef Medline

31. Wechsler D. Wechsler Test of Adult Reading: WTAR. San Antonio Psychological Corporation; 2001

32. Greenberg SM, Vernooij MW, Cordonnier C, et al; Microbleed Study Group. Cerebral microbleeds: a guide to detection and interpretation. Lancet Neurol 2009;8:165-74 CrossRef Medline

33. Greenberg SM, Finklestein SP, Schaefer PW. Petechial hemorrhages accompanying lobar hemorrhage: detection by gradient-echo MRI. Neurology 1996;46:1751-54 CrossRef Medline

34. Trifan G, Gattu R, Haacke EM, et al. MR imaging findings in mild traumatic brain injury with persistent neurological impairment. Magn Reson Imaging 2017;37:243-51 CrossRef Medline

35. Toth A, Kornyei B, Kovacs N, et al. Both hemorrhagic and nonhemorrhagic traumatic MRI lesions are associated with the microstructural damage of the normal appearing white matter. Behav Brain Res 2018;340:106-16 CrossRef Medline

36. Topal NB, Hakyemez B, Erdogan C, et al. MR imaging in the detection of diffuse axonal injury with mild traumatic brain injury. Neurol Res 2008;30:974-78 CrossRef Medline

37. Shoamanesh A, Kwok CS, Benavente O. Cerebral microbleeds: histopathological correlation of neuroimaging. Cerebrovasc Dis 2011; 32:528-34 CrossRef Medline

38. Roob G, Fazekas F. Magnetic resonance imaging of cerebral microbleeds. Curr Opin Neurol 2000;13:69-73 CrossRef Medline

39. Roob G, Lechner A, Schmidt R, et al. Frequency and location of microbleeds in patients with primary intracerebral hemorrhage. Stroke 2000;31:2665-69 CrossRef Medline

40. Toth A, Kovacs N, Tamas V, et al. Microbleeds may expand acutely after traumatic brain injury. Neurosci Lett 2016;617:207-12 CrossRef Medline

41. Daugherty AM, Raz N. Incident risk and progression of cerebral microbleeds in healthy adults: a multi-occasion longitudinal study. Neurobiol Aging 2017;59:22-29 CrossRef Medline 